\title{
Radiological Consequence Evaluation for Dragonfly Mission
}

\section{$12 / 9 / 2021$}

Caleb McHugh

Nuclear Safety Associate Engineer, BGS

Tammy Wheeler

Senior Nuclear Project Manager, BGS

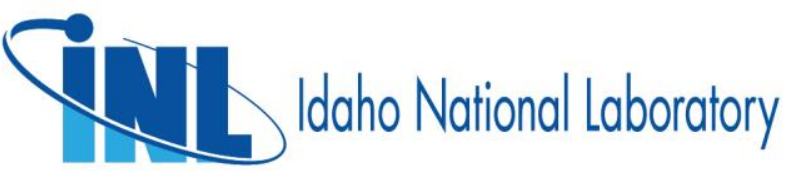




\section{DISCLAIMER}

This information was prepared as an account of work sponsored by an agency of the U.S. Government. Neither the U.S. Government nor any agency thereof, nor any of their employees, makes any warranty, expressed or implied, or assumes any legal liability or responsibility for the accuracy, completeness, or usefulness, of any information, apparatus, product, or process disclosed, or represents that its use would not infringe privately owned rights. References herein to any specific commercial product, process, or service by trade name, trade mark, manufacturer, or otherwise, does not necessarily constitute or imply its endorsement, recommendation, or favoring by the U.S. Government or any agency thereof. The views and opinions of authors expressed herein do not necessarily state or reflect those of the U.S. Government or any agency thereof. 


\title{
Radiological Consequence Evaluation for Dragonfly Mission
}

\author{
Caleb McHugh
}

Tammy Wheeler

$12 / 9 / 2021$

\begin{abstract}
Idaho National Laboratory
Originating Organization

Idaho Falls, Idaho 83415
\end{abstract}

http://www.inl.gov

Prepared for the

U.S. Department of Energy

Under DOE Idaho Operations Office

Contract DE-AC07-05ID14517 
Page intentionally left blank 


\section{CONTENTS}

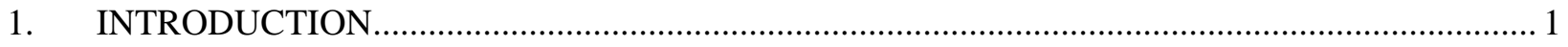

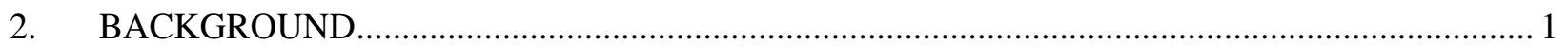

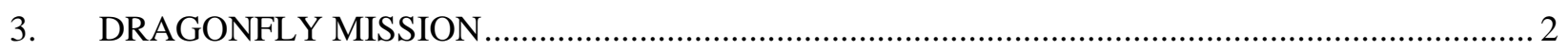

4. DOSE CONSEQUENCE SCOPING CALCULATIONS SUMMARY RESULTS.......................... 2

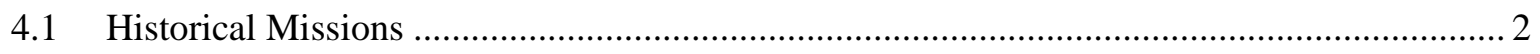

4.1.1 Previous Mission Summaries ................................................................................ 2

4.1.2 Summary of Mars Missions Dose Consequence Analysis .......................................... 3

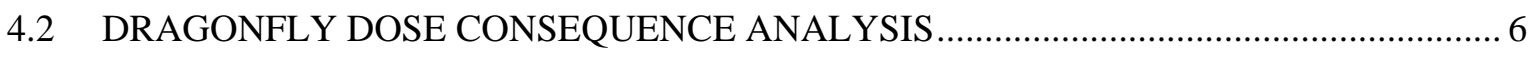

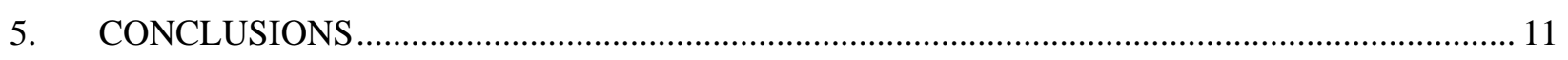

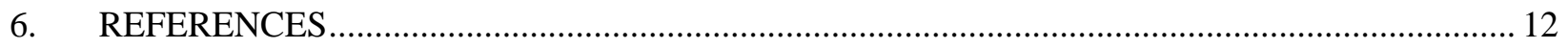

\section{TABLES}

Table 1. Summary of Mars 2020 dose consequence analysis................................................................ 3

Table 2. Consequence factors affecting mission risk...........................................................................5

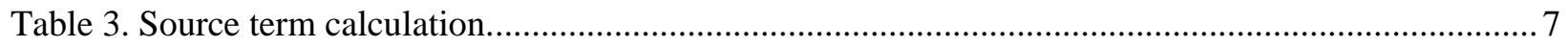

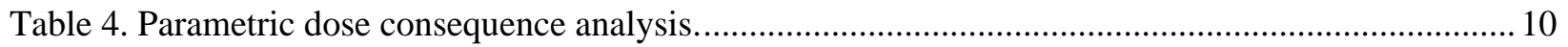


Page intentionally left blank 
INL/EXT-21-65050

Rev. 0

$12 / 9 / 2021$

\section{Radiological Consequence Evaluation for Dragonfly Mission \\ 1. INTRODUCTION}

The scoping calculations presented in this report were developed to provide a conservative estimate of radiological dose consequences associated with launch accidents involving one multi-mission radioisotope thermoelectric generator (MMRTG) and possibly up to 43 light-weight radioisotope heater units (LWRHUs) for the upcoming National Aeronautics and Space Administration (NASA) Dragonfly mission. This report summarizes the probabilistic dose consequence analysis from SAND2019-11148, "Nuclear Risk Assessment 2019 Update for the Mars 2020 Mission Environmental Impact Statement," referred to in this document as the Mars 2020 nuclear risk analysis (NRA) and compares those results to a parametric deterministic analysis used to analyze potential dose consequences for the Dragonfly mission.

\section{BACKGROUND}

The general-purpose heat source (GPHS) modules contained in the MMRTG were developed to act as a long-term source of thermal power for space missions. These missions require a large power source, which will operate over a very long mission life. In addition to the GPHS units, LWRHUs were developed to provide a means for maintaining acceptable operating temperatures for spacecraft and associated electronic equipment in applications where solar power is infeasible. In 2019, the NASA New Frontiers 4 Announcement of Opportunity (AO) two-step down-selection was complete with the selection of a mission to Saturn's moon Titan proposed by APL. This mission has been named Dragonfly due to the rotorcraft lander concept for scientific exploration of Titan. The MMRTG payload for the Dragonfly mission is similar to ones that have been used in two prior NASA missions: Mars Science Laboratory (MSL) in 2011 and Mars 2020. The similarity lies primarily in the use of one MMRTG. These two prior missions also reflect the trend in GPHS-enabled missions in the $21^{\text {st }}$ century. The consequence analysis for the Mars 2020 mission is considered representative for both missions as its payload is most similar and its analysis is also the most technically advanced, and thus will be the analysis referenced in this document.

The spacecraft in both previous missions were launched into space using the Atlas V 541 launch vehicle. The Atlas V 541 launch vehicle employs four solid rocket boosters (SRBs). The thrust necessary to propel this launch vehicle (or any other) with its spacecraft and nuclear payload into space is provided by engines fueled by liquid and/or solid propellants. Pre-launch and launch-related accidents typically involve very energetic conditions, including explosions (liquid propellant and solid propellant), fires (liquid or solid propellant), fragment impacts, and ground impacts.

NASA and Department of Energy (DOE) follow a rigorous process to quantify the risks associated with launch-related accidents, including Earth atmosphere reentry and post-reentry impacts. Missionspecific analyses include mission-related NRAs, launch-related safety analysis reports (SARs), and safety evaluation reports (SERs) issued by ad-hoc panels established to provide independent review and evaluation of the launch of nuclear power systems into space. These analyses quantify the risks (e.g., latent cancer fatalities, land contamination, etc.) associated with the use of space nuclear power systems in the specific mission, including the MMRTG and LWRHUs as applicable. 


\section{DRAGONFLY MISSION}

The Dragonfly mission will land on Titan, the largest moon of Saturn, and operate an eight-bladed rotorcraft spacecraft, powered by a single MMRTG and up to 43 LWRHUs. The mission is planned to launch in 2027 and arrive at Titan by 2034. The mission of Dragonfly will be to sample and examine dozens of sites around Titan, hoping to learn more about the early stages of the development of life. The baseline mission will last 32 months, but as with previous GPHS-enabled missions, it is likely that the power generated by the MMRTG could allow for extensions of the mission beyond original planning, if approved by NASA.

The MMRTG consists of a stack of eight "Step 2" GPHS modules containing ${ }^{238} \mathrm{PuO}_{2}$ ceramic fuel pellets clad in iridium-alloy fuel clad (FC), graphite impact shells (GIS), and a fine-weave pierced fabric (FWPF) aeroshell. Each aeroshell contains two GISs, which in turn include two iridium-clad fuel pellets. Each fuel pellet contains roughly $151 \mathrm{~g} \mathrm{PuO}_{2}$ fuel $\left(82.2 \%{ }^{238} \mathrm{Pu}\right)$, and there are 32 total pellets in each MMRTG for a total $\mathrm{PuO}_{2}$ mass of $4.8 \mathrm{~kg}$ and an activity of 59,000 Ci.

The LWRHU is a radioisotope-fueled system consisting of a 1-Watt (W) pellet of heat source plutonium dioxide $\left(\mathrm{PuO}_{2}\right)$ fuel, consisting primarily of $\mathrm{Pu}-238$; a clad of platinum-30 rhodium (Pt-30Rh); an insulation system of pyrolytic graphite; and an aeroshell/impact body of FWPF. Nominal exterior dimensions are $26 \mathrm{~mm}$ ( 1 in.) diameter by $32 \mathrm{~mm}$ (1.25 in.) long. Each LWRHU weighs about $40 \mathrm{~g}$ and contains approximately $2.7 \mathrm{~g} \mathrm{PuO}_{2}$. With $43 \mathrm{LWRHUs} \mathrm{present,} \mathrm{this} \mathrm{results} \mathrm{in} 1,400 \mathrm{Ci}$ of ${ }^{238} \mathrm{Pu}$.

The total ${ }^{238} \mathrm{Pu}$ activity involved in the accident will be assumed to be the sum of one MMRTG $(59,000 \mathrm{Ci})$ and $43 \mathrm{LWRHUs}(1,400 \mathrm{Ci})$ for a total of 60,400 Ci. Cases assumed to include only one MMRTG are bounded by the $60,400 \mathrm{Ci}$ of ${ }^{238} \mathrm{Pu}$.

\section{DOSE CONSEQUENCE SCOPING CALCULATIONS SUMMARY RESULTS}

Based on the extensive launch-related analyses that have been conducted for previous relevant NASA missions in which MMRTGs were used, it is desirable to leverage this information to establish a conservative and bounding safety analysis baseline against which the Dragonfly mission can be evaluated. The results presented here provide a conservative estimate of dose consequences to the off-site public based on previous mission-based risk and safety analyses. The results will provide further insight into the hazards associated with the Dragonfly mission and provide supporting information for use in future safety analysis development efforts.

\subsection{Historical Missions}

As discussed in Section 2 , two previous NASA missions (MSL 2011 and Mars 2020) have similar MMRTG payloads to the Dragonfly mission. Mission-specific analyses include NEPA-related NRAs and launch-related SARs. These analyses quantified the risks (e.g., latent cancer fatalities, land contamination, etc.) associated with the use of space nuclear power systems.

\subsubsection{Previous Mission Summaries}

4.1.1 Mars Science Laboratory. The Mars Science Laboratory (MSL) mission is described in SAND2008-3522, "Final Safety Analysis Report for the Mars Science Laboratory MMRTG Launch Approval." The MSL mission landed a rover (Curiosity) on the surface of Mars to conduct a Mars habitability investigation. The MSL mission used a single GPHS-MMRTG (total $\mathrm{PuO}_{2}$ mass of $4.8 \mathrm{~kg}$ and 
an activity of 59,000 $\mathrm{Ci}$ ) to deliver thermal power to the rover and its associated scientific tools for the duration of the mission. The GPHS-MMRTG was notable for being the first to deploy the "Step 2" GPHS module design. The MSL was launched aboard an Atlas V 541 launch vehicle from Space Launch Center (SLC)-41 at Cape Canaveral Air Force Station (CCAFS) on November 26, 2011. The Curiosity rover landed on Mars on August 6, 2012. The GPHS-MMRTG has been able to meet its power requirements, and the mission has been extended indefinitely. As of 2021, the mission is still ongoing.

4.1.1.2 Mars 2020. The Mars 2020 mission landed a rover (Perseverance) on the surface of Mars to explore the landing area site and gather imaging, spectroscopy, composition data, and other measurements about selected Martian soils, rocks, and atmosphere. The Mars 2020 mission was very similar to the MSL mission in that it also employed a single GPHS-MMRTG on a similar rover, launched and delivered in similar spacecraft. As such, the analyses for both were very similar. The Mars 2020 spacecraft was launched aboard an Atlas V 541 launch vehicle from SLC-41 at CCAFS on July 30, 2020. The Perseverance rover landed on Mars on February 18, 2021. The GPHS-MMRTG has met its Beginning of Mission (BOM) power requirements, and the mission is ongoing.

The Mars 2020 spacecraft was almost identical to that employed for the MSL mission. It consisted of a cruise stage (CS), an aeroshell (includes a heatshield and a backshield), a descent stage, and the science rover.

\subsubsection{Summary of Mars Missions Dose Consequence Analysis}

The MSL mission and the Mars 2020 mission were similar since almost identical payloads and launch vehicles were used for the two missions. However, the Mars 2020 analysis was performed at a later time and is considered more advanced due to advanced modelling techniques. The Mars 2020 NRA, in turn, resulted in more accurate dose consequence analysis results and thus can be considered appropriate for the purpose of comparison in this analysis. Therefore, only the dose consequence analysis results for the Mars 2020 mission are provided in this section.

Table 1 presents a summary of the calculated source terms and maximum individual radiological dose consequences resulting from postulated releases of the plutonium oxide fuel, as presented in the MARS 2020 NRA for each phase of the Mars 2020 mission.

Table 1 . Summary of Mars 2020 dose consequence analysis.

\begin{tabular}{|c|c|c|c|c|c|}
\hline \multirow[b]{2}{*}{ Phase } & \multirow{2}{*}{$\begin{array}{c}\text { Total } \\
\text { Probability } \\
\text { of Release } \\
\text { (TPOR) }\end{array}$} & \multicolumn{2}{|c|}{ Source Term, $\mathrm{Ci}^{\mathrm{a}}$} & \multicolumn{2}{|c|}{ Public Dose, rem $^{a}$} \\
\hline & & $\begin{array}{c}\text { Mean Given } \\
\text { a Release }\end{array}$ & $\begin{array}{c}99^{\text {th }} \text { Percentile } \\
\text { Given } \\
\text { Release }\end{array}$ & $\begin{array}{c}\text { Mean Given a } \\
\text { Release }\end{array}$ & $\begin{array}{l}99^{\text {th }} \text { Percentile } \\
\text { Given a Release }\end{array}$ \\
\hline Phase 0 & $6.26 \mathrm{E}-05$ & 52.3 & 1,080 & $1.4 \mathrm{E}-01$ & $2.4 \mathrm{E}+00$ \\
\hline $\begin{array}{c}\text { Bounding Phase } 1 \\
\text { Accident }\end{array}$ & $8.84 E-07$ & 6,540 & 20,200 & $1.2 E+00$ & $2.6 E+01$ \\
\hline Phase 1 & 8.98E-04 & 1,130 & 6,970 & $2.1 \mathrm{E}-01$ & $4.1 \mathrm{E}+00$ \\
\hline Phase 2 & $2.57 \mathrm{E}-06$ & 79.8 & 621 & $4.8 \mathrm{E}-02$ & $1.3 \mathrm{E}+00$ \\
\hline Phase 3 & 7.33E-06 & 371 & 3,820 & $2.4 \mathrm{E}+00$ & $5.5 \mathrm{E}+01$ \\
\hline Phase 4 & $6.61 \mathrm{E}-05$ & 46.1 & 414 & $1.6 \mathrm{E}+00$ & $1.9 \mathrm{E}+01$ \\
\hline Phase 5 & $8.52 \mathrm{E}-06$ & 48.7 & 423 & $1.0 \mathrm{E}+00$ & $1.9 \mathrm{E}+01$ \\
\hline
\end{tabular}

a. Mean source term/dose and 99th percentile source term/dose are for all accidents in which a release occurs. Per NRA text: " $100 \%$ of the source term was assumed to be airborne, which may be conservative since much of the source term 
would be trapped by the graphite materials and other debris. Furthermore, simulations show that particles larger than 100 microns would fall to the ground rapidly (generally within a few meters)."

b. The probabilities associated with the 99th percentile source term and dose are two orders of magnitude lower than the TPOR shown in the table.

c. The Bounding Phase 1 Accident is noted in italics to indicate that it is a single accident analyzed in Phase 1 as opposed a complete phase.

The accident scenarios and their respective release probabilities and consequential doses were analyzed by dividing mission launches into six distinct phases as shown in Table 1 . The phases are defined as the following:

- Phase 0: Pre-Launch, $\mathrm{T}<\mathrm{t}_{1}$, from installation of the MMRTG to just prior to start of the Stage 1 liquid rocket engines (LREs) at $\mathrm{t}_{1}$.

- Phase 1: Early Launch, $t_{1}<\mathrm{T}<\mathrm{t}_{\mathrm{x}}$, from start of Stage $1 \mathrm{LRE}(\mathrm{s})$, to just prior to $\mathrm{t}_{\mathrm{x}}$, where $\mathrm{t}_{\mathrm{x}}$ is the time after which there would be no potential for debris or intact vehicle configurations resulting from an accident to impact land in the launch area, and water impact would occur.

- Phase 2: Late Launch, $\mathrm{t}_{\mathrm{x}}<\mathrm{T}$, when the launch vehicle reaches an altitude of nominally $30,480 \mathrm{~m}$ $(100,000 \mathrm{ft})$, an altitude above which reentry heating could occur.

- Phase 3: Suborbital Reentry, from nominally 30,480 m (100,000 ft) altitude to the end of Stage 2 burn 1 and command destruct system (CDS) is disabled.

- Phase 4: Orbital Reentry, from end of Stage 2 burn 1 to Stage 2 / spacecraft separation.

- Phase 5: Long-Term Reentry, after spacecraft separation until no chance of Earth reentry.

The mean source terms and associated doses are composites weighted by probability for all accident insults in each phase. The highest mean dose shown in Table 1 is 1.2 rem for the bounding Phase 1 accident which is shown in italics to denote that it is not a Phase composite dose but rather an accident dose associated with a Phase. In this Phase 1 accident, the launch vehicle impacts the ground (launch pad) before it can break up, resulting in a full-stack intact impact (FSII) without the activation of the CDS or Centaur automatic destruct system (CADS) (see Section Error! Reference source not found.). This scenario is known as FSII without CDS/CADS. The total probability of this specific accident is less than 1E-06. The associated source term is the total quantity of airborne material; when the respirable portion of the airborne material is taken into account, the radiation dose consequence is reduced.

The highest radiation dose shown in Table 1 is the $99^{\text {th }}$ percentile dose of 55 rem associated with Phase 3 with a $99^{\text {th }}$ percentile probability less than $1 \mathrm{E}-07$. The bounding Phase 1 accident $99^{\text {th }}$ percentile dose is 26 rem with a $99^{\text {th }}$ percentile probability less than $1 \mathrm{E}-08$. The $99^{\text {th }}$ percentile radiation dose for a Phase 1 accident is $4.1 \mathrm{rem}$ associated with a probability of less than 1E-5. The mean Phase 1 accident dose is 0.2 rem associated with a probability of less than $1 \mathrm{E}-3$. The most likely outcome of a launch is a successful mission with no accident and no accidental radiation dose, with an associated probability greater than $99.8 \%$. 
By inspection, all of the dose consequences for the analyzed Mars 2020 mission are well below the NSPM-20, "Launch of Spacecraft Containing Space Nuclear Systems,", safety guidelines (the most restrictive being $5 \mathrm{rem}$ for an event with a probability of $10^{-2}$ to $10^{-4}$, and $25 \mathrm{rem}$ for an event with a probability of $10^{-4}$ to $10^{-6}$ ).

In addition to comparing the dose consequences of the Mars 2020 NRA to the NSPM- $20^{1}$ safety guidelines, the Mars 2020 analysis is pertinent as it provides another comparative, recent benchmark for mission risk.

The radiological consequences resulting from the given accident scenarios in the Mars 2020 NRA were calculated in terms of 1) maximum individual dose, 2) collective dose, 3) health effects, and 4) land area affected at or above specified levels. The radiological consequences are based on atmospheric transport and dispersion simulations. Biological effects models, based on methods prescribed by the International Commission on Radiological Protection (ICRP), are used to predict the number of incremental latent cancer fatalities over 50 years (health effects) induced following a fuel release accident and assuming no mitigation measures. The two relevant consequence factors for this analysis are maximum individual dose and the cropland intervention factor.

The maximum individual dose is the mean (for historical meteorological conditions) maximum (for location) dose delivered to a hypothetical individual for a given accident, considering the probability distribution over all release conditions.

The updated analysis for the Mars 2020 mission included calculations of the land area that could be contaminated at levels that require cropland remediation. In this case "contaminated cropland requiring remediation" is defined at a threshold $\mathrm{Pu}-238$ surface contamination of $7.3 \mu \mathrm{Ci} / \mathrm{m}^{2}$ for the specific crops in the vicinity of Kennedy Space Center (KSC) (see SAND2019, "Nuclear Risk Assessment 2019 Update for the Mars 2020 Mission Environmental Impact Statement"7 Table 4-2). The extent of land contaminated at this level or higher was calculated using probabilistic methods specific to the type of launch vehicle and spacecraft, as well as meteorological conditions. The average area contaminated at the $7.3 \mu \mathrm{Ci} / \mathrm{m}^{2}$ level was less than $0.01 \mathrm{~km}^{2}$ for Phases 0,1 , and 2 if an accident occurred (see SAND2019, "Nuclear Risk Assessment 2019 Update for the Mars 2020 Mission Environmental Impact Statement"7).

The Mars 2020 NRA Section A.3 meteorology discussion makes the following statement that infers this analysis was specific to the Mars 2020 mission July-August launch window: "Typically the modeling of launch area releases is based on a range of time-and spatially-dependent meteorological conditions representative of the period of launch opportunity." The consequence factors taken from the MARS 2020 NRA mission risk are shown in Table 2.

Table 2. Scaled consequence factors affecting mission risk.

\begin{tabular}{|c|c|}
\hline $\begin{array}{c}\text { Maximum } \\
\text { Individual Dose } \\
\text { Factor: } m \\
(\mathrm{rem} / \mathrm{Ci})\end{array}$ & $\begin{array}{c}\text { Factor: } a_{I} \\
\left(\mathrm{~km}^{2} / \mathrm{Ci}\right)\end{array}$ \\
\hline $3.16 \mathrm{E}-04$ & $1.27 \mathrm{E}-05$ \\
\hline
\end{tabular}

The values are calculated by scaling the Mars 2020 NRA Table 4-8 values. The "Maximum Individual Dose Factor," $m$, which equals 3.16E-04 rem/Ci, is the mean consequence for this set (maximum individual dose for the overall mission) divided by the mean source term radioactivity level (in $\mathrm{Ci}$ ) given a release for the overall mission. Applying the normalized dose-to-curie-source term factor 
INL/EXT-21-65050

Rev. 0

$12 / 9 / 2021$

to a hypothetical total source term consisting of the total quantity of $\mathrm{PuO}_{2}$ that would be present for the Dragonfly mission (i.e., the total material-at-risk: $59,000 \mathrm{Ci}^{238} \mathrm{Pu}$ from the MMRTG and $1,400 \mathrm{Ci}{ }^{238} \mathrm{Pu}$ from the $43 \mathrm{LWRHU}$ for a total of 60,400 Ci) would result in a maximum individual dose of approximately 19 rem. This hypothetical value falls below the NSPM- $20^{1}$ safety guideline of 25 rem for an accident with a likelihood probability of $10^{-4}$ to $10^{-5}$. The probability of creating such a source term would be significantly lower than the bounding probability of $8.98 \mathrm{E}-04$ for all Phase 0 and Phase 1 accidents presented in the Mars 2020 NRA (Phase 2 accidents are much more unlikely and add significantly less risk to the overall mission probability of release).

\subsection{DRAGONFLY DOSE CONSEQUENCE ANALYSIS}

A dose consequence analysis was prepared for the upcoming Dragonfly mission to develop a conservative estimate of consequences associated with specific accident environments. The results support a parametric analysis designed to envelop the accident events in the probabilistic analysis performed for the Mars 2020 NRA. The fire and explosion values are presented to bound the direct impact to an MMRTG and LWRHUs, the thermal buoyancy effects of an event associated with a thermal/fire ball insult, and an explosion of liquid fuel or solid rocket propellant resulting in a buoyant elevated release and subsequent transport of plutonium. The analysis presented for the Dragonfly dose consequence analysis includes a 1, 5, 10, 20,1,000, and 10,000 megawatt (MW) fire; and a 100, 500, $1,000,5,000,10,000$, and 82,500 lb (lb) TNT-Equivalent (TNT-Eq) explosion and is intended to bound the potential consequences for the Dragonfly mission. The fire and explosion scenarios are developed to present scenarios with buoyant plume rise and explosive plume rise and radius. Impact accidents are assumed to include subsequent fires and are therefore bounded by the fire releases.

For the selected fire model inputs, the heat release rate, Q (MW) of a fire changes as the size of the fire evolves as a function of time. Heat release rates of fires are needed as a prerequisite for estimating fire temperatures, airborne release fractions, and buoyancy, which aide in determining the dispersion of the buoyant plume. Likewise, the quantity of TNT-Eq is needed as a prerequisite for determining the initial dimensions, height, and radius of the dispersive explosive plume.

The dose pathways to be considered are inhalation, direct shine, and ground shine. The dominant pathway for impacts, fires, and explosions involving plutonium is the inhalation pathway. Contribution from direct shine and ground shine are considered negligible. The inhalation doses associated with each release type requires the determination of the quantity of airborne respirable radioactivity that is released into the air. This quantity is referred to as the source term and is determined using the following equation in DOE-HDBK-3010, "Airborne Release Fractions/Rates and Respirable Fractions for Nonreactor Nuclear Facilities."

$$
\mathrm{ST}=\mathrm{MAR} * \mathrm{DR} * \mathrm{ARF} * \mathrm{RF} * \mathrm{LPF}
$$

Where:

ST: $\quad$ Source term, the amount of radioactive material, in grams or curies, driven airborne at the accident source that is effectively inhalable.

MAR: Material-at-risk, the amount of radionuclide material available to be acted on by a given stress.

DR: Damage ratio, the fraction of MAR actually acted upon by the accident-generated conditions. 
ARF: Airborne release fraction, the coefficient used to estimate the amount of radioactive material suspended in air as an aerosol and thus available for transport due to physical stresses from a specific accident.

RF: Respirable fraction, the fraction of airborne radionuclides as particles that can be transported through the air into the human respiratory system.

LPF: Leak path factor, the fraction of radionuclides in the aerosol transported through some confinement deposition of filtration mechanism.

For purposes of this calculation and in accordance with DOE-HDBK-3010, the LPF is assumed to be 1 . The values for the ARF and RF are accident-specific and are as follows. For the lower energy 1, 5, and 10-MW fire accident scenarios, the ARF and RF used were 0.0005 and 0.5 , respectively. The values are presented in DOE-HDBK-3010 on Page 4-2 for "airborne release of particulates formed by selfsustained oxidation (molten metal with oxide coat), self-induced convection." For the higher energy 10 and 20-MW fire scenarios and the explosion scenarios, the ARF and RF used were 0.0035 and 1 , respectively. These values are presented in DOE-HDBK-3010 on Page 4-26 for disturbed molten metal surface with high turbulence. As the threshold for applying the two different ARF and RF values is between 5 and $20 \mathrm{MW}$, the $10 \mathrm{MW}$ fire is analyzed using both sets of values. The radioactive material is not in a mated configuration with the explosive propellant and would therefore release due to a postulated thermal insult from a fireball or explosion in close proximity. A damage ratio analysis was not performed for this analysis as the DR was assumed to be 1 to ensure the analysis remained conservative. The MAR was $60,400 \mathrm{Ci}\left(59,000 \mathrm{Ci}^{238} \mathrm{Pu}\right.$ from the MMRTG and 1,400 $\mathrm{Ci}{ }^{238} \mathrm{Pu}$ from the 43 LWRHUs).

Table 3 summarizes the source term calculation for each release type.

Table 3. Source term calculation.

\begin{tabular}{|c|c|c|c|c|c|c|c|}
\hline Release Type & $\begin{array}{c}\text { MAR } \\
\text { (Ci) }\end{array}$ & DR & ARF & $\mathrm{RF}$ & LPF & $\begin{array}{l}\text { ST } \\
\text { (Ci) }\end{array}$ & Reference \\
\hline $\begin{array}{l}\text { Impact } \\
1 \text { MW Fire } \\
5 \text { MW Fire } \\
10 \text { MW Fire } \\
100 \text { MW Fire } \\
\text { 1,000 MW Fire } \\
10,000 \text { MW Fire }\end{array}$ & 60,400 & 1 & $5 \mathrm{E}-4$ & 0.5 & 1 & 15 & $\begin{array}{l}\text { DOE-HDBK-3010-94 Metal Thermal } \\
\text { Stress: Plutonium Page } 4-2 \text {, airborne } \\
\text { release of particulates formed by self- } \\
\text { sustained oxidation (molten metal with } \\
\text { oxide coat), self-induced convection. }\end{array}$ \\
\hline $\begin{array}{l}\text { Impact } \\
10 \text { MW Fire } \\
20 \text { MW Fire } \\
100 \mathrm{lb} \text { Exp } \\
500 \mathrm{lb} \text { Exp } \\
1,000 \mathrm{lb} \text { Exp } \\
5,000 \mathrm{lb} \text { Exp } \\
10,000 \mathrm{lb} \text { Exp } \\
82,500 \mathrm{lb} \operatorname{Exp}\end{array}$ & 60,400 & 1 & $\begin{array}{c}3.5 \mathrm{E}- \\
3\end{array}$ & 1 & 1 & 211 & $\begin{array}{l}\text { DOE-HDBK-3010 Disturbed Molten } \\
\text { Metal Surface with High Turbulence } \\
\text { Page } 4-26\end{array}$ \\
\hline
\end{tabular}

The source terms reported in the Mars 2020 NRA were determined by a Monte Carlo simulation using 100,000 trials or more for each of the various accident scenarios and assumed $100 \%$ of the source term to be airborne. This is a conservative assumption since much of source term would be trapped by the graphite materials and other debris. The comparison of the deterministic source term results in this 
INL/EXT-21-65050

Rev. 0

$12 / 9 / 2021$

calculation to the probabilistic Mars 2020 NRA source term results is not a viable comparison to make due to the major differences in the calculation methodology. equation:

Using this calculated source term, the dose to the receptors is then calculated using the following

$$
\mathrm{CED}=\mathrm{ST} * \chi / \mathrm{Q} * \mathrm{BR} * \mathrm{DCF}
$$

Where:

CED: Committed effective dose, represents the 50-year effective dose from inhalation of radionuclides.

ST: $\quad$ Source term (discussed above).

$\chi / \mathrm{Q}: \quad$ Dispersion coefficient, the factor that accounts for dispersion of the respirable radioactive material from the point of release to the dose receptor location.

BR: Breathing rate, represents the amount of air breathed by an adult. In accordance with DOE-STD-3009-2014, "Preparation of Nonreactor Nuclear Facility Documented Safety Analysis," 3 the default value of $3.3 \mathrm{E}-04 \mathrm{~m}^{3} / \mathrm{s}$ is used.

DCF: Dose conversion factor, the factor that converts the amount of radioactivity deposited in the body through inhalation. Dose consequence is estimated based on the dose conversion factor (DCF) for the off-site public selected from the ICRP-72, "Age-Dependent Doses to Members of the Public from Intake of Radionuclides." The ICRP-72 methodology results in a 50-year committed effective dose (CED) for inhaled radionuclides. If pathways other than internal are added to the CED, then the result is the total effective dose (TED).

Because of the dominance of the inhalation dose, the CED results are roughly equivalent to the TED determination. The DCF value selected for use in this calculation was $5.92 \mathrm{E}+07 \mathrm{rem} / \mathrm{Ci}$ (for $\mathrm{Pu}-238$ oxide), based on the manufacturing process of the $\mathrm{PuO}_{2}$ that results in S solubility. While other isotopes may be present in the heat source plutonium oxide fuel, the contribution to the inhalation dose would be minimal compared to the $\mathrm{Pu}-238$; therefore, assuming the presence of only $\mathrm{Pu}-238$ is conservative. The ICRP-72 DCF values bound the DCF values for the worker and have therefore been used for both dose calculations.

The $\chi / \mathrm{Q}$ for each release type was determined using the DOE Toolbox code MACCS2 [described in NUREG/CR-6613 (SAND97-0594)], developed and maintained by Sandia National Laboratory, and POSTMAX (described in LA-UR-09-1601), developed by Los Alamos National Laboratory (LANL). Buoyancy effects usually arise if significant sensible heat is contained in the cloud being released. For nonreactor DOE facilities, the primary sources of these cloud types are through postulated explosion or fire events. The estimation of the buoyancy component requires knowledge of the effluent and ambient temperatures at the point of release. If the effluent temperature is higher, positive (i.e., upward) buoyancy occurs, while for a cold or dense cloud, negative buoyancy will occur. The latter condition is normally associated with certain types of chemical releases, more so than for radiological releases. The stability class of the atmosphere is also a very important parameter to account for, as it affects the magnitude of the buoyancy plume rise. To envelope the potential dispersion of the accidents, selected sensible heat and explosives quantities with two different atmospheric stability classes have been included in a parametric study. The following inputs and assumptions were made in the development of the $\chi / Q$ values. 
- $\quad \chi / \mathrm{Q}$ values were determined for a non-buoyant, ground-level, point source (impact) release; fires with a 1, 5, 10, 20, 100, 1,000, and 10,000-MW sensible heat load; and a 100, 500, 1,000, 5,000, 10,000, and 82,500-lb TNT-Eq explosion. The latter fire and explosion sizes represents the maximum quantities allowable to MACCS2.

- $\quad$ The $\chi / \mathrm{Q}$ reported for each release type was at the ground-level, in the plume centerline.

- Rural dispersion coefficients from DOE-HDBK-1224-2018, “Accident Analysis Handbook,"5 were assumed. The $\sigma_{\mathrm{y}}$ and $\sigma_{\mathrm{z}}$ values were input as parameter lookup tables using Eimutis \& Konicek (E \& $\mathrm{K})$ parameter values for distances less than $500 \mathrm{~m}$ and Tadmor-Gur (T-G) parameter values for distances greater than or equal to $500 \mathrm{~m}$.

- A deposition velocity of $0.1 \mathrm{~cm} / \mathrm{sec}$ for unfiltered release of particles.

- A surface roughness of $3 \mathrm{~cm}$.

- Two meteorological conditions were assumed: Pasquill stability class $F$ and $1 \mathrm{~m} / \mathrm{s}$ windspeed which represents the $95^{\text {th }}$ percentile moderately stable meteorological conditions with minimal mixing and plume spread and Pasquill stability class D and $4.5 \mathrm{~m} / \mathrm{s}$ windspeeds which represents the $50^{\text {th }}$ percentile neutral meteorological conditions and is the most frequent of the stability classes.

- Plume meander was suppressed.

- Building wake effects were not credited in the plume dispersion.

- $\quad$ Plume rise associated with the fires was calculated within the MACCS2 code using the Briggs equation.

- The release height for outdoor explosions was analyzed as described in DOE-HDBK-1224 Section 6.12.3. This approach is based on the methodology described in LA-UR-98-1901, "Plutonium Explosive Dispersal Modeling Using the MACCS2 Computer Code," which uses the Church model.

- The boundary distance for the worker is assumed to be $2,000 \mathrm{~m}$, and the boundary distance for the maximally-exposed off-site individual (MOI) is assumed to be at or beyond 2,000 $\mathrm{m}$ where touchdown occurs.

The MACCS 2 code calculates the $\chi / \mathrm{Q}$ at the locations of interest, and therefore, for energetic releases, such as fires and explosions for receptors in the near-field, the plume could pass over the receptor before reaching ground-level. For this reason, POSTMAX, a LANL postprocessor code, was used to determine the associated $\chi / \mathrm{Q}$ value at touchdown for each receptor which may occur at or beyond the distance of the receptor. Both codes meet the Software Quality Assurance (SQA) requirements as described in DOE-STD-3009-2014.

The following table uses the source terms from Table 3 and summarizes the accidents included in the parametric study, a description of the type of release each represents, the associated $\chi / \mathrm{Q}$ value, and the doses for the two meteorological conditions. The worker $\chi / \mathrm{Q}$ at 2,000 $\mathrm{m}$ is reported at exactly 2,000 m; the MOI $\chi / \mathrm{Q}$ is reported as the maximum $\chi / \mathrm{Q}$ at or beyond 2,000 $\mathrm{m}$ where touchdown of the plume occurs. The MOI is defined in DOE-STD-3009-2014 and is analogous to the term Maximally-Exposed Individual (MEI). 
Table 4. Parametric dose consequence analysis.

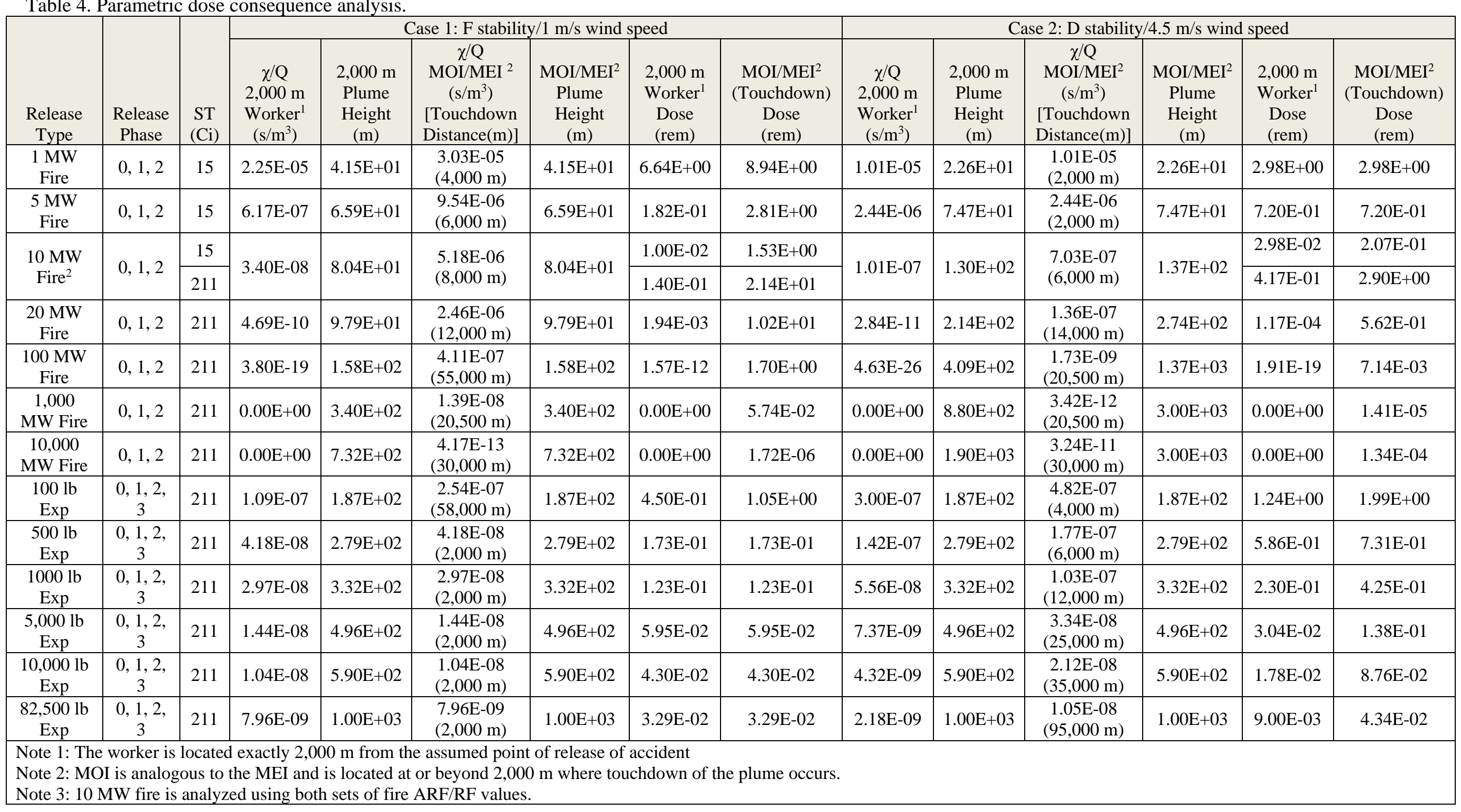


INL/EXT-21-65050

Rev. 0

$12 / 9 / 2021$

The $\chi / \mathrm{Q}$ values using $\mathrm{F}$ stability $/ 1 \mathrm{~m} / \mathrm{s}$ result in more conservative estimates of dispersion for fires due to the two methods MACCS2 uses for calculating the amount of plume rise. For neutral or unstable stability classes A-D, plume rise is treated using the "two thirds" law for bent-over plumes, and for stable conditions (stability class E-F), the plume rise is treated using the Briggs equation for the final rise of a bent-over buoyant plume. The amount of plume rise for stable conditions is lower than for neutral or unstable conditions; therefore, the F stability $/ 1 \mathrm{~m} / \mathrm{s} \chi / \mathrm{Q}$ values are higher than the D stability $/ 4.5 \mathrm{~m} / \mathrm{s} \chi / \mathrm{Q}$ values.

The touchdown $\chi / \mathrm{Q}$ values for $\mathrm{F}$ stability for the higher quantities of explosives occur at closer distances since the F stability class is associated with inversion breakup fumigation conditions in which an elevated plume is rapidly brought to the ground. The $\chi / \mathrm{Q}$ values are more conservative for the explosions due to the atmospheric mixing, and the mixing layer height assumed in the calculation.

The results from the Dragonfly mission parametric dispersion code analysis show all accidents result in maximum doses which are less than 21.4 rem.

\section{Contaminated Land:}

MACCS2 reports the centerline ground concentration after passage of the plume averaged over the spatial interval's length. Assuming the standard settling speed, $0.001 \mathrm{~m} / \mathrm{s}$, and a $1.0 \mathrm{~m} / \mathrm{s}$ windspeed and F stability, the bounding (maximum) contamination level for all release scenarios would be $6.41 \mu \mathrm{Ci} / \mathrm{m}^{2}$ regardless of location.

\section{CONCLUSIONS}

The following conclusions are made relative to the deterministic dose consequence calculations presented in the previous section. In all cases, the calculated dose consequences are below $25 \mathrm{rem}$. It can be concluded that the Dragonfly mission deterministic dose consequences compare to the previous probabilistic analysis given for the Mars 2020 mission and the Dragonfly deterministic analysis can be considered bounding for the analysis performed for the Mars 2020 mission in spite of the differences in the two analysis approaches. The Mars 2020 accident analysis used a probabilistic risk assessment for release of the plutonium dioxide fuel by running numerous sequences of events in a Monte Carlo fashion for each selected, potential launch accident with randomly chosen values for key parameters within each sequence. The dose consequence calculations presented here for the Dragonfly mission use a deterministic analysis which is based on a range of sensible heat loads for fires and a range of explosives quantities to bound the dose values associated with very unlikely accidents. By nature of the two methods, the Dragonfly deterministic approach produces more conservative dose consequences than the mean doses reported in the Mars 2020 NRA; however, some conclusions can be drawn from a comparison of the two types of results. As the deterministic approach results in more conservative doses, the Dragonfly dose results are compared to the probabilistic $99^{\text {th }}$ percentile dose results. The maximum $99^{\text {th }}$ percentile accident scenario dose of Phase 0 in the Mars 2020 NRA is 2.4 rem, which is bounded by the parametric study dose consequences. The maximum $99^{\text {th }}$ percentile accident dose for a single scenario of Phase 1 in the Mars 2020 NRA is 26 rem, which is within $20 \%$ of the maximum dose determined by the parametric study dose consequences of $21.4 \mathrm{rem}$. As stated in the NRA, "The $99^{\text {th }}$ percentile radiological consequence value reflects the potential for larger consequences at lower probabilities." The source term total mass release for this accident scenario is $100 \%$ of $\mathrm{PuO}_{2}$ available for release. Overall, there is general agreement with the parametric cases analyzed for Dragonfly and the probabilistic results documented in the Mars 2020 NRA.

As described previously, the deterministic analysis assumed two meteorological cases: F stability $/ 1 \mathrm{~m} / \mathrm{s}$ and D stability/ $4.5 \mathrm{~m} / \mathrm{s}$. The 2019 NRA probabilistic analyses used sample weather data 
from several recent years for the months of July and August and is therefore relative to the launch site. The approach documented in this calculation is applicable for any launch site. The Dragonfly deterministic, parametric dose consequences are less than $21.4 \mathrm{rem}$ for $\mathrm{F}$ stability $/ 1 \mathrm{~m} / \mathrm{s}$, an infrequent atmospheric condition, and an extremely conservative dose associated with a DR of 1 resulting from a 10 MW fire. The dose consequences for the more frequent atmospheric conditions of D stability $/ 4.5 \mathrm{~m} / \mathrm{s}$ and similar consequence dose assessment are less than 2.9 rem.

\section{REFERENCES}

1. NSPM-20, "Launch of Spacecraft Containing Space Nuclear Systems," National Security Presidential Memorandum, August 20, 2019.

2. DOE-HDBK-3010-94, "Airborne Release Fractions/Rates and Respirable Fractions for Nonreactor Nuclear Facilities,” Volume 1 -Analysis of Experimental Data, U.S. Department of Energy, December 1994.

3. DOE-STD-3009-2014, "Preparation of Nonreactor Nuclear Facility Documented Safety Analysis," U.S. Department of Energy, December 2014.

4. ICRP-72, "Age-Dependent Doses to Members of the Public from Intake of Radionuclides," International Commission on Radiological Protection, 1995.

5. DOE-HDBK-1224-2018, “Accident Analysis Handbook,” U.S. Department of Energy, August 2018.

6. LA-UR-98-1901, "Plutonium Explosive Dispersal Modeling Using the MACCS2 Computer Code," Los Alamos National Laboratories, 1998.

7. SAND2019-11148, "Nuclear Risk Assessment 2019 Update for the Mars 2020 Mission Environmental Impact Statement," Sandia National Laboratories, 2019.

8. SAND2008-3522, "Final Safety Analysis Report for the Mars Science Laboratory MMRTG Launch Approval," Sandia National Laboratories, July 2008.

9. NUREG/CR-6613 (SAND97-0594), “Code Manual for MACCS2: Volume 1, User’s Guide,” Sandia National Laboratories, 1998.

10. LA-UR-09-1601, “POSTMAXV2.0 User’s Guide,” Los Alamos National Laboratories, 2009. 